\title{
Research on High Temperature and High Density White Oil Based Drilling Fluid and Its Application in Well 201H7-6
}

\author{
Bobo Qin, Yidi Wang, Chunzhi Luo, Gang Liu \\ College of Chemistry and Environmental Engineering, Yangtze University, Jingzhou, China \\ Email: 1131076242@qq.com
}

How to cite this paper: Qin, B.B., Wang, Y.D., Luo, C.Z. and Liu, G. (2019) Research on High Temperature and High Density White Oil Based Drilling Fluid and Its Application in Well 201H7-6. Open Journal of Yangtze Gas and Oil, 4, 174-182. https://doi.org/10.4236/ojogas.2019.43013

Received: April 28, 2019

Accepted: July 21, 2019

Published: July 24, 2019

Copyright $\odot 2019$ by author(s) and Scientific Research Publishing Inc. This work is licensed under the Creative Commons Attribution International License (CC BY 4.0).

http://creativecommons.org/licenses/by/4.0/ C. (i) Open Access

\begin{abstract}
As the depth and horizontal length of shale gas development wells increase, the requirement for the temperature resistance and the ability of the drilling fluids to stabilize the shale formation becomes higher. A new type of high temperature and high density white oil based drilling fluid system has been developed in laboratory. Research shows that the drilling fluid system has good rheological property, low filtration loss, strong anti-debris pollution capability and good plugging performance at high temperature and high density. The system has been successfully applied in the 201H7-6 well. Application results show that the drilling fluid rheology, high temperature and high pressure fluid loss and demulsification voltage meet the field requirements. The drilling fluid performance is stable in drilling an $1800 \mathrm{~m}$ horizontal section, and no stuck or shale swelling and wellbore collapsing are induced. It is the first well drilled successfully with domestic white oil-based drilling fluid in Zigong Region. It also sets several new records including the deepest well, the shortest drilling cycle, and the fastest drilling speed in that region, which provides valuable experience for the future drilling activities.
\end{abstract}

\section{Keywords}

Oil-Based Drilling Fluid, Demulsification Voltage, Rheology, Fluid Loss, Inhibition, Pollution, Plugging

\section{Introduction}

The geological structure of Zigong Area is complex, and there are many layers with high fluid loss risk, high formation pressure and hydrogen sulfide. The risk of well control is high and the well construction is difficult due to frequent pipe stuck and wellbore stability problems, especially in the horizontal section. Well 
201H7-6 is a shale gas well deployed by SINOPEC in this block, in which vertical depth is $3290 \mathrm{~m}$, horizontal length is $1800 \mathrm{~m}$, formation pressure coefficient is 1.6, maximum bottom temperature is $147^{\circ} \mathrm{C}$ with a fault of $50 \mathrm{~m}$, and thinnest reservoir thickness of $5 \mathrm{~m}$. The length of the horizontal section in several previous wells drilled in this block is less than $1500 \mathrm{~m}$, and all those wells are drilled with diesel-based drilling fluid system. During the drilling process, all those wells encounter serious problems such as shale swelling, and the drilling cycle lasted for more than three months. In addition, the formation temperature of the block is high, and the diesel-based drilling fluids not only encounter vaporisation problems in high temperature conditions, but also induce serious safety hazards and serious environmental pollution. Moreover, the high-temperature sand-carrying and suspended capacity of the drilling fluid decrease as the viscosity of the diesel oil decreases, which brings a series of problems to drilling activity [1]-[6]. To overcome these problems, a white oil based drilling fluid system is designed, which is more difficult to emulsify under high temperature conditions than diesel. In this design, macromolecular emulsifiers with anti-warming groups, wetting agents, organic soils with good temperature resistance, high temperature fluid loss additives and high temperature plugging agents are chosen to develop high temperature and high density white oil based drilling fluid. The rheology, fluid loss, electrical stability, sedimentation stability, and film-forming plugging properties of the system are evaluated at different temperatures, different densities and different oil-water ratios [7]-[12]. A series of plans for the successful application of the system are prepared. The system was applied in the building section and horizontal section of Well 201H7-6 in October 2018. Based on the encountered difficulties such as high wellbore pressure, thin thickness of the production box and complicated trajectory of the wellbore, the performance of the drilling fluid is adjusted, which leads to smooth construction of the well with high quality and high efficiency. It sets several records including the deepest drilling depth, the shortest drilling cycle, and the fastest drilling speed of Sichuan Company, and it is the first successful application of white oil-based drilling fluid in the area. It also provides valuable experience for future well construction in the region, which strongly supports the efficient development of the block.

\section{Design Methodology}

The data of the adjacent wells drilled in Well 201H7-6 shows that during the drilling of horizontal wells in the block, the risk of wellbore instability is high, the wellbore is difficult to be cleaned, and the friction force on the drill string is high. Oil-based drilling fluid requires good emulsion stability, rheology and plugging properties on high temperature, high pressure and high density conditions. Thus, the development of drilling fluid treatment agents and the study of system formulations are taken in account based on these previously encountered problems. 


\subsection{Increase the Strength of the Oil-Water Interface Film and Improve the Stability of the Emulsion}

A surfactant with large molecular weight is developed based on the relationship between molecular structure and surface activity. It is then combined with several other surfactants to form a stable interfacial film at the oil-water interface, which ensures that the fluid flows into the wellbore during the drilling process is oil phase. Meanwhile, macromolecules can enhance the grid structure of the system, thereby improving the ability to carry cuttings and suspended debris.

\subsection{Guarantee the Wettability of the System to Barite and Cuttings}

The well has a minimum formation pressure coefficient of 1.6 and an additional pressure coefficient of $0.15-0.20$. In order to prevent the shale swelling, the designed drilling fluid density is up to $2.3 \mathrm{~g} / \mathrm{cm}^{3}$. To address this problem, a polyamide-based wetting agent is developed. The wetting agent has a large number of adsorbing groups, which are well adsorbed on the surfaces of the weighting material and the cuttings, so that the barite and the cuttings can be fully dispersed and suspended in the drilling fluid.

\subsection{Enhance the Fluid Loss Prevention Performance of the System}

The stability of mud shale is not only related to the density of the supporting drilling fluid, but also has a close relationship with the film-forming plugging property of the drilling fluid. The combination of ultra-fine rigidity and flexible plugging agent can form a sealing film on the surface of shale surrounding the wellbore, micro-cracks and pores, which can reduce the fluid loss of drilling fluid, prevent shale hydration and spalling, and stabilize the wellbore.

\subsection{The Process of On-Site Preparation of Drilling Fluid}

At the beginning of the drilling, the density of drilling fluid is low, and the fluid is mixed with low oil-to-water ratio. As the well depth and horizontal length increase, the temperature and density of the drilling fluid gradually increase. At the same time, the oil-water ratio needs to be gradually increased to ensure good rheological properties and wellbore stability of the drilling fluid [13] [14] [15].

\section{Formula Optimization and Performance Evaluation}

Based on the design methodology of drilling fluid system discussed in the previous sections, investigations and optimizations are conducted on the key treatment agents such as emulsifier, wetting agent, fluid loss additive and plugging agent. Then, the basic formula of the high-temperature and high-density white oil-based drilling fluid system is obtained by optimizing the dosages of the emulsifier, wetting agent, organic soil, fluid loss reducer and the like, and the oil-water ratio.

\subsection{Formula Optimization}

Two drilling fluid systems with oil-water ratios of 8:2 and 9:1 are prepared in 
laboratory. The barite is weighted to different densities and rolled at $135^{\circ} \mathrm{C}$ and $150^{\circ} \mathrm{C}$ for $16 \mathrm{~h}$. Apparent viscosity $(A V)$, plastic viscosity $(P V)$, dynamic shear force $(Y P)$, dynamic plastic ratio $(Y P / P V)$, static shear force $(G E L)$, demulsification voltage $(E S)$ and high temperature and high pressure fluid loss $\left(F L_{\mathrm{HTHP}}\right)$ are measured after the aging of the drilling fluid at $65^{\circ} \mathrm{C}$. The experimental results are shown in Table 1 and Table 2.

Basic formula of drilling fluid is: $3 \#$ white oil $+(2.5 \%-4.0 \%)$ primary emulsifier $+(1.5 \%-3.0 \%)$ co-emulsifier $+(0.5 \%-1.0 \%)$ wetting agent $+(0.8 \%-$ $1.5 \%)$ organic soil $+(2.0 \%-2.5 \%) \mathrm{CaO}+1.5 \%$ fluid loss additive $+1.5 \%$ plugging agent $+\mathrm{CaCl}_{2}$ saline $\left(\mathrm{CaCl}_{2}\right.$ mass fraction is $\left.25 \%\right)$. The amount of emulsifier, wetting agent, $\mathrm{CaO}$ and organic soil can be adjusted according to the oil-water ratio and density in the actual conditions.

Table 1. The basic performance of the system after $135^{\circ} \mathrm{C}$ hot rolling.

\begin{tabular}{ccccccccc}
\hline $\begin{array}{c}\text { oil-water } \\
\text { ratio }\end{array}$ & $\begin{array}{c}\text { density } \\
/\left(\mathrm{g} \cdot \mathrm{cm}^{-3}\right)\end{array}$ & $\begin{array}{c}E S \\
/ \mathrm{V}\end{array}$ & $\begin{array}{c}A V \\
/(\mathrm{mPa} \cdot \mathrm{s})\end{array}$ & $\begin{array}{c}P V \\
/(\mathrm{mPa} \cdot \mathrm{s})\end{array}$ & $\begin{array}{c}Y P \\
/ \mathrm{Pa}\end{array}$ & $\begin{array}{c}Y P \\
P V\end{array}$ & $\begin{array}{c}G E L \\
/\left(10^{-3} \cdot \mathrm{s}^{-1}\right)\end{array}$ & $\begin{array}{c}F L_{\mathrm{HTHP}} \\
/ \mathrm{Pa} / \mathrm{Pa})\end{array}$ \\
\hline \multirow{2}{*}{$8: 2$} & 1.9 & 657 & 59 & 50.0 & 9.0 & 0.18 & $5 / 13$ & 2.8 \\
& 2.0 & 689 & 63 & 53.5 & 9.5 & 0.18 & $6 / 15$ & 2.6 \\
& 2.1 & 725 & 66 & 56.0 & 10.0 & 0.18 & $6 / 16$ & 2.4 \\
& 2.2 & 746 & 75 & 57.0 & 11.0 & 0.20 & $7 / 18$ & 2.4 \\
& 1.9 & 812 & 43 & 36.0 & 7.0 & 0.20 & $3 / 7$ & 2.6 \\
& 2.0 & 864 & 48 & 40.0 & 8.0 & 0.20 & $4 / 7$ & 2.8 \\
& 2.1 & 892 & 65 & 43.5 & 8.5 & 0.20 & $4 / 9$ & 2.6 \\
& 2.2 & 956 & 71 & 46.0 & 9.0 & 0.20 & $5 / 10$ & 2.4 \\
\hline
\end{tabular}

Table 2. The basic performance of the system after $150^{\circ} \mathrm{C}$ hot rolling.

\begin{tabular}{ccccccccc}
\hline $\begin{array}{c}\text { oil-water } \\
\text { ratio }\end{array}$ & $\begin{array}{c}\text { density } \\
/\left(\mathrm{g} \cdot \mathrm{cm}^{-3}\right)\end{array}$ & $\begin{array}{c}E S \\
/ \mathrm{V}\end{array}$ & $\begin{array}{c}A V \\
/(\mathrm{mPa} \cdot \mathrm{s})\end{array}$ & $\begin{array}{c}P V \\
/(\mathrm{mPa} \cdot \mathrm{s})\end{array}$ & $\begin{array}{c}Y P \\
/ \mathrm{Pa}\end{array}$ & $\begin{array}{c}Y P \\
P V\end{array}$ & $\begin{array}{c}G E L \\
/\left(10^{-3} \cdot \mathrm{s}^{-1}\right)\end{array}$ & $\begin{array}{c}F L_{\mathrm{HTHP}} \\
/ \mathrm{mL} / \mathrm{Pa})\end{array}$ \\
\hline & 1.9 & 667 & 58 & 48 & 10 & 0.18 & $5 / 13$ & 2.6 \\
$8: 2$ & 2.0 & 681 & 61 & 52 & 9 & 0.18 & $6 / 15$ & 2.8 \\
& 2.1 & 734 & 65 & 54 & 11 & 0.18 & $6 / 16$ & 2.4 \\
& 2.3 & 759 & 68 & 56 & 12 & 0.20 & $7 / 18$ & 2.6 \\
& 1.9 & 842 & 44 & 36 & 8 & 0.20 & $3 / 7$ & 2.8 \\
& 2.0 & 867 & 47 & 38 & 9 & 0.20 & $4 / 7$ & 2.4 \\
& 2.1 & 889 & 51 & 42 & 9 & 0.20 & $4 / 9$ & 2.6 \\
& 2.3 & 941 & 55 & 46 & 9 & 0.20 & $5 / 10$ & 2.4 \\
\hline
\end{tabular}

It can be seen from Table 1 and Table 2 that in the case of the same oil-water ratio, as the density increases, the demulsification voltage of the system gradually increases. There are minor increases in the apparent viscosity, plastic viscosity, dynamic shear force, which can meet the requirements of on-site drilling; the 
fluid loss gradually decreases, and both test results are less than $3.0 \mathrm{~mL}$, indicating that the system has good plugging and fluid loss reduction effect, and a good function of stabilizing the wellbore. Under the same density, the temperature rises, the system's demulsification voltage, viscosity, and fluid loss show no obvious changes, indicating that the system has good temperature resistance and can adapt to different formation temperatures between $135-150^{\circ} \mathrm{C}$. At the same density, the oil-water ratio increases, the demulsification voltage increases, and both results are above $600 \mathrm{~V}$, indicating that the system has good emulsion stability. Viscosity, fluid loss, and other parameters can also meet the requirements of the field applications.

The white oil-based system has a high demulsification voltage, low filtration loss and reasonable viscosity at different densities, different temperatures, and different oil-water ratios compared to the diesel based fluids. It shows that the system has good emulsion stability, can adapt to various complicated situations in the well, and provides guarantee for smooth drilling operation.

\subsection{Inhibition Performance Evaluation}

The shale cuttings of Longmaxi Formation in Pengshui Block, Liangshan Formation in the Zigong Block and the Longmaxi Formation in Zigong Block are selected, and the inhibition performance of the system is evaluated by linear expansion experiments and cuttings recovery experiments.

Expansion rate experiment with cuttings: 1) the cuttings are ground to less than 200 mesh, and the sieved powders are dried at a temperature of $105 \pm 20^{\circ} \mathrm{C}$; 2) weigh $100.0 \mathrm{~g}$ of rock cuttings and press it at a pressure of $54 \mathrm{MPa}$ for $10 \mathrm{~min}$ in a mold of the sampler to prepare a column sample; 3 ) the linear expansion rate is measured after immersion in distilled water and oil-based drilling fluid for $16 \mathrm{~h}$ on the OFIT shale dilatometer; 4) 6 - 10 mesh shale cuttings are used for a cuttings recovery test, take $350 \mathrm{~mL}$ drilling fluid in the aging tank, add $30 \mathrm{~g} 6$ 10 mesh shale cuttings, stir evenly with glass rod, cover the lid, put it in the roll in the sub-furnace; 5) roll the sample at $150^{\circ} \mathrm{C}$ for $16 \mathrm{~h}$, and recover the undistributed cuttings by a 40 -mesh sieve, rinse it with petroleum ether, and dry it at $105^{\circ} \mathrm{C} \pm 2^{\circ} \mathrm{C} ; 6$ ) weigh the process cuttings to obtain the rolling recovery of cuttings. The experimental results are shown in Table 3.

Table 3. The expansion rate and recovery rate of cuttings in drilling fluid.

\begin{tabular}{cccccc}
\hline \multirow{2}{*}{ Cuttings level } & area & \multicolumn{2}{c}{ Linear expansion ratio/\% } & \multicolumn{2}{c}{ Cuttings rolling recovery/\% } \\
\cline { 3 - 6 } & & water & Oil-based drilling fluid & water & Oil-based drilling fluid \\
\hline Longmaxi & pengshui & 7.9 & 0.2 & 56.7 & 98.3 \\
Liangshan & zigong & 9.3 & 0.1 & 62.4 & 98.8 \\
Longmaxi & zigong & 8.1 & 0.2 & 81.7 & 97.9 \\
\hline
\end{tabular}

It can be seen from Table 3 that the rolling recovery rate of the white oil-based drilling fluid exceeds $97 \%$, and the expansion rate of the cuttings does not exceed $0.2 \%$. It shows that the drilling fluid has good inhibition performance 
and can effectively inhibit the hydration expansion and dispersion of shale.

\subsection{Anti-Pollution Performance Evaluation}

Oil-based drilling fluid may be contaminated by drill cuttings during on-site drilling, resulting in changes in drilling fluid performance and failing to meet safe drilling requirements. In the laboratory, a drilling fluid with a oil-water ratio of $8: 2$ and a density of $2.1 \mathrm{~g} / \mathrm{cm}^{3}$ is used, and cuttings powder with different mass fractions from Longmaxi Formation in Zigong Block is added (the cuttings are over 200 mesh). The experimental results are shown in Table 4 .

Table 4. The effect of cuttings content on drilling fluid performance.

\begin{tabular}{cccccccc}
\hline $\begin{array}{c}\text { Cuttings } \\
/ \%\end{array}$ & $\begin{array}{c}E S \\
/ \mathrm{V}\end{array}$ & $\begin{array}{c}A V \\
/(\mathrm{mPa} \cdot \mathrm{s})\end{array}$ & $\begin{array}{c}P V \\
/(\mathrm{mPa} \cdot \mathrm{s})\end{array}$ & $\begin{array}{c}Y P \\
/ \mathrm{Pa}\end{array}$ & $\begin{array}{c}Y P \\
P V\end{array}$ & $\begin{array}{c}G E L \\
/\left(10^{-3} \cdot \mathrm{s}^{-1}\right)\end{array}$ & $\begin{array}{c}F L_{\mathrm{HTHP}} \\
/ \mathrm{mL} / \mathrm{Pa})\end{array}$ \\
\hline 0.0 & 734 & 65 & 54 & 11 & 0.18 & $6 / 16$ & 2.4 \\
3.0 & 735 & 66 & 55 & 11 & 0.20 & $6 / 16$ & 2.3 \\
5.0 & 739 & 68 & 56 & 12 & 0.21 & $6 / 17$ & 2.4 \\
8.0 & 743 & 71 & 59 & 12 & 0.20 & $7 / 17$ & 2.5 \\
10.0 & 751 & 88 & 74 & 14 & 0.19 & $8 / 19$ & 2.5 \\
\hline
\end{tabular}

It can be seen from Table 4 that with the addition of cuttings, the demulsification voltage, apparent viscosity, plastic viscosity and dynamic shear force of the system gradually increase, the dynamic plastic ratio and the high temperature and high pressure filtration loss change slightly. When the amount of cuttings is less than $5 \%$, the performance of drilling fluid changes little. When the dosage is $8 \%$, the apparent viscosity and plastic viscosity increase quickly than those in previous conditions. When the dosage is $10 \%$, the apparent viscosity and plastic viscosity increase more obviously. It shows that the cutting debris limit of this system is $8 \%$. Thus, attention is needed to remove cuttings out of this low-density solid phase during on-site applications to ensure safe and rapid drilling.

\subsection{Fluid Loss Prevention Performance Evaluation}

The simulation of shale micro-cracks and pores is a difficult point in the evaluation of drilling fluid loss prevention. By comparing various sealing performance evaluation methods, it is found out that the artificial sand disc with different permeabilities can be used for the drilling fluid sealing experiment with good representativeness and repeatability. Two oil-based drilling fluids with an oil-water ratio of $8: 2$ and a density of $2.1 \mathrm{~g} / \mathrm{cm}^{3}$ are formulated, one is with $2 \%$ plugging agent and the other is without plugging agent, separately. The two drilling fluids are rolled at $135^{\circ} \mathrm{C}$ for $16 \mathrm{~h}$, and the artificial sand discs with permeability of $400 \mathrm{mD}, 750 \mathrm{mD}$ and $2 \mathrm{D}$ are selected. The drilling fluid plugging tester (PPT) is used to determine the filtration loss of sand disc at different times (PFL). The smaller the fluid loss is, the better the plugging property is. The experimental results are shown in Figure 1. 


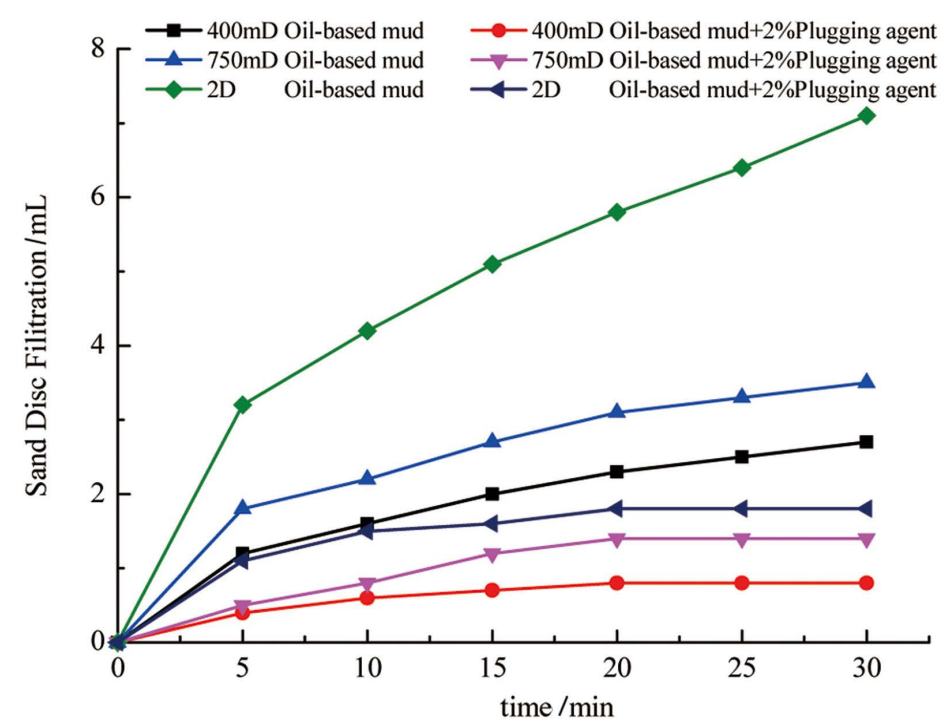

Figure 1. The sealing performance of drilling fluid for sand discs with different permeabilities.

It can be seen from Figure 1 that the loss of the sand disc with the plugging agent is much less than that of the unfilled. The smaller the permeability of the sand disc is, the smaller the loss of the sand disc is. However, the fluid loss of the drilling fluid with the plugging agent on the sand disc with different permeabilities is almost the same. It indicates that the drilling fluid with plugging agent has good sealing property for sand discs with different permeabilities, and the sealing performance of the low permeability sand discs is especially better, which can prevent the solid phase and liquid phase in the drilling fluid from entering the wellbore. Thus, the shale swelling caused by the filtration can be inhibited, and the wellbore remains stable.

\section{Field Application}

Well 201H7-6 is a horizontal shale gas production well deployed in Zigong City, Sichuan Province. The length of the horizontal section is $1800 \mathrm{~m}$. The well ( $\varphi 215.9 \mathrm{~mm}$ borehole) adopts a four-stage wellbore structure, the target layer of the horizontal section in the well is Longmaxi Formation, and the rock type is dark grey shale. Because of the formation of shale bedding and micro-fractures in Longmaxi Formation, the rock is easy to swell and collapse during the drilling process. Furthermore, the horizontal section of the well is long, the formation pressure is high, and the B point is only $50 \mathrm{~m}$ away from the fault. Therefore, in the actual drilling, there are a number of drilling difficulties such as wellbore stability, insufficient well cleaning, high friction on the drill string, and high risk of fluid loss. Based on the results of lab study, four high-temperature and high-density white oil-based drilling fluids designed by the author are used during the drilling activity. The entire well interval is $3290 \sim 5486 \mathrm{~m}$ with a cumulative footage of $2196 \mathrm{~m}$ and a horizontal section of $1800 \mathrm{~m}$. The performance of drilling fluids in different intervals is shown in Table 5. 
Table 5. The oil-based mud performance from the four-open sections of Well $201 \mathrm{H} 7$.

\begin{tabular}{cccccccccc}
\hline $\begin{array}{c}\text { well } \\
\text { Deep } \\
/ \mathrm{m}\end{array}$ & $\begin{array}{c}\text { density } \\
/\left(\mathrm{g} \cdot \mathrm{cm}^{-3}\right)\end{array}$ & $\begin{array}{c}\text { Funnel } \\
\text { viscosity/s }\end{array}$ & $\begin{array}{c}\text { Demulsification } \\
\text { voltage/V }\end{array}$ & $\begin{array}{c}A V \\
/(\mathrm{mPa} \cdot \mathrm{s})\end{array}$ & $\begin{array}{c}P V \\
/(\mathrm{mPa} \cdot \mathrm{s})\end{array}$ & $\begin{array}{c}\text { Dynamic } \\
\text { ratio/l }\end{array}$ & $\begin{array}{c}\frac{Y P}{P V} \\
/\left(10^{-3} \cdot \mathrm{s}^{-1}\right)\end{array}$ & $\begin{array}{c}G E L \\
/(\mathrm{Pa} / \mathrm{Pa})\end{array}$ & $\begin{array}{c}\mathrm{Cl}^{-} \text {concentration } \\
/\left(\mathrm{mg} \cdot \mathrm{L}^{-1}\right)\end{array}$ \\
\hline 3204 & 1.91 & 53 & 728 & 47.5 & 41 & 0.16 & $5 / 13$ & 3.4 & $/$ \\
3377 & 2.02 & 65 & 842 & 63.5 & 54 & 0.18 & $5 / 14$ & 2.6 & 20,000 \\
3630 & 2.10 & 63 & 820 & 66.0 & 58 & 0.14 & $6 / 16$ & 2.4 & 23,000 \\
3711 & 2.18 & 64 & 945 & 63.5 & 56 & 0.13 & $6 / 16$ & 2.4 & 24,000 \\
4395 & 2.16 & 66 & 1132 & 70.0 & 62 & 0.13 & $7 / 16$ & 3.0 & 25,000 \\
4838 & 2.14 & 64 & 1024 & 65.0 & 54 & 0.2 & $6 / 16$ & 2.0 & 26,000 \\
5000 & 2.13 & 66 & 1024 & 75.0 & 61 & 0.23 & $7 / 17$ & 1.6 & 28,000 \\
5486 & 2.15 & 67 & 1089 & 72.0 & 59 & 0.22 & $6 / 16$ & 1.6 & 29,000 \\
\hline
\end{tabular}

The results of drilling in the horizontal section of Well 201H7-6 show that the white oil-based drilling fluid has good emulsifying effect and high demulsification voltage. At the end of the drilling, the demulsification voltage is more than $1000 \mathrm{~V}$, and the performance is stable. It has low apparent viscosity, plastic viscosity, high dynamic-plastic ratio and static shearing force. It shows that the system has good flow performance; the anti-collapse formation protection ability is strong, the fluid loss is low, the wellbore is stable, and there is basically no swelling and breakouts during the drilling process. Well logging and casing activities are smooth after the drilling is completed. It sets the records of the deepest drilling depth, the shortest cycle, and the fastest drilling speed in that region, which provides valuable experience for future drilling.

\section{Conclusions}

1) The oil-water ratio of the oil-based drilling fluid system is $8: 2$ and 9:1. At different densities, after rolling at $135^{\circ} \mathrm{C}$ and $150^{\circ} \mathrm{C}$, it has good emulsion stability, suitable viscosity and shear force, and low filtration loss at high temperature and high pressure, which can meet the needs of field applications.

2) The system has good inhibition performance and resistance to cuttings pollution, and its rolling recovery rate is over $97 \%$, and the resistance to cuttings pollution is $8 \%$.

3) The system has good sealing properties for different permeability sand discs.

4) The system has been successfully applied in Well 201H7-6. The rheology of drilling fluid meets the requirements of hole cleaning; the high temperature and high pressure fluid loss is less than $3.5 \mathrm{~mL}$, the mud cake quality is good, the sealing is strong, the wellbore is stable, the casing and well logging are smooth. It has set the records of the deepest drilling depth, the shortest cycle, and the fastest drilling speed in the region, which provides valuable experience for future drilling.

\section{Conflicts of Interest}

The authors declare no conflicts of interest regarding the publication of this paper. 


\section{References}

[1] He, S., Li, S., Wang, X., et al. (2013) Development of High Performance Oil-Based Drilling Fluid and Its Application in Pengwan 3HF Well. Drilling Fluid and Completion Fluid, 30, 1-4.

[2] Liu, X.Q., Chen, D.H., Chen, Y., et al. (2011) Research and Application of Environmentally Friendly All-White Oil-Based Drilling Fluid. Drilling Fluid and Completion Fluid, 28, 10-12.

[3] Taugbl, K., Lilledal, L., Juel, H., et al. (2004) The Completion of Subsea Production Wells Eased by the Use of a Unique, High-Density, Solids-Free, Oil Based Completion Fluid. Society of Petroleum Engineers.

[4] Zhang, Y., Wang, J., Shu, F., et al. (2012) Research and Application of White Oil-Based Oil-in-Water Drilling Fluid Technology. Journal of Oil and Gas, 34, 235-237.

[5] Zhang, H., Zhou, Z., Liu, F., et al. (2016) Research and Application of White Oil Base Oil Drilling Fluid System. Drilling and Mining Technology, 39, 99-102.

[6] Xu, T. (2015) High-Density White Oil-Based Drilling Fluid Research. China University of Petroleum, Beijing.

[7] Fossum, P.V., Moum, T.K., Sletfjerding, E., et al. (2007) Design and Utilization of Low Solids OBM for Aasgard Reservoir Drilling and Completion. Society of Petroleum Engineers.

[8] Zanten, R.V., Miller, J.J., Baker, C., et al. (2012) Impoved Stability of Invertemulsion Fluids. Society of Petroleum Engineers.

[9] Zhou, Z. (2012) Practical Application Research of Environmentally Friendly All-White Oil-Based Drilling Fluid. China Petroleum and Chemical Industry Standards and Quality, 2, 174.

[10] Wang, M., Xiao, H., Xiao, D.S., et al. (2011) Application of Low Density White Oil Based Drilling Fluid in Underbalanced Drilling. Science and Technology Innovation Guide, 19, 47-48.

[11] Ren, J. (2017) Application of GL-1 Well to $260^{\circ} \mathrm{C}$ White Oil-Based Water-in-Oil Drilling Fluid. Prospecting Engineering (Rock and Soil Drilling Engineering), 44, 51-54.

[12] Gao, Y., Yang, P., Li, J., et al. (2016) Indoor Research on High Temperature and High Density All White Oil Based Drilling Fluid System. Drilling \& Production Technology, 39, 88-90.

[13] Wang, X., Li, X., Lin, Y., et al. (2013) Research and Application of High Performance Oil-Based Drilling Fluid for Shale Horizontal Wells. Oil Drilling Technolo$g y, 41,17-22$.

[14] Zhang, W., Wu, J., Jiang, G., et al. (2018) Applicability of MEGADRIL Oil-Based Drilling Fluid in High Temperature and High Pressure Gas Fields in the Western South China Sea. Journal of Yangtze University, 15, 43-49.

[15] Li, L., Xu, M., Fu, F., et al. (2017) Establishment and Evaluation of a White Oil-Based Constant Rheological Drilling Fluid System for Deep Water. Contemporary Chemical Industry, 46, 268-270. 